\title{
HASIL BELAJAR SISWA SMA PADA PEMBELAJARAN FISIKA MENGGUNAKAN MODEL PROBLEM BASED LEARNING (PBL) DENGAN PENDEKATAN STEM (SCIENCE, TECHNOLOGY, MATHEMATICS AND ENGINEERING)
}

\author{
${ }^{1)}$ Yullya Erlina Eka Putri, 1) Albertus Djoko Lesmono, ${ }^{2)}$ Ismanto \\ ${ }^{1)}$ Program Studi Pendidikan Fisika FKIP Universitas Jember \\ ${ }^{2)}$ SMA Negeri 2 Jember, Jl. Jawa 16 Telp. (0331) 321375, Jember 68121 \\ E-mail: yullyaerlina@gmail.com
}

\begin{abstract}
This article discusses the learning outcomes of high school students using the Problem Based Learning (PBL) model with the STEM (Science, Technology, Engineering and Mathematics) approach. The purpose of this article is to describe how student learning outcomes in the cognitive domain in learning physics at SMA Negeri 2 Jember using the PBL model with the STEM approach. This type of research uses true experiment research and the sample of this study is students of class X MIPA 6 in SMA Negeri 2 Jember. Data collected through the method of Student Worksheets (LKS) and tests. The instrument used in this study was a student learning achievement test in the form of a posttest. The data obtained were analyzed using the N-gain test in order to know the increase in student learning outcomes before and after using the PBL model with the STEM approach. The results of this study is the use of the PBL model with the STEM approach can improve student learning outcomes X MIPA 6 in SMA Negeri 2 Jember.
\end{abstract}

Key word: PBL Model with STEM approach, learning outcomes.

\section{PENDAHULUAN}

Pendidikan merupakan salah satu upaya memanusiakan seseorang agar sesuai dengan nilai-nilai kemanusiaan. Hal tersebut dapat diwujudkan dengan cara belajar, yaitu interaksi antara guru dan siswa dimana komunikasi pun terjadi antara keduanya (transfer) secara intens dan mengarah pada target yang sudaha ditentukan (Trianto, 2010: 17). Oleh karena itu, pendidikan perlu dilakukan secara sadar dan memiliki tujuan yang jelas. Ilmu pengetahuan yang dipelajari dalam proses pendidikan salah satunya ialah Ilmu Pengetahuan Alam (IPA), diantaranya biologi, kimia dan fisika.

Fisika merupakan bagian dari ilmu sains yang mempelajari gejala dan fenomena alam serta mengungkap rahasia alam secara alamiah (Centaury, 2015). Berdasarkan pernyataan tersebut, fisika merupakan ilmu yang mempelajari mengenai gejala alam sehingga memungkinkan untuk melakukan percobaan-percobaan dan menjelaskan bagaimana gejala tersebut dapat terjadi menurut penggambaran dari pemikiran manusia secara matematis.

Pembelajaran fisika yang baik seharusnya bukan hanya sekedar menghafal, namun lebih menekankan pada proses terbentuknya pengetahuan dan penguasaan siswa terhadap suatu konsep, sehingga pengetahuan dapat diperoleh dengan peran aktif dari siswa itu sendiri. Kegiatan menghafal pada pembelajaran fisika pada 
dasarnya kurang sesuai dengan hakikat belajar fisika, karena tidak disertai dengan proses, produk dan sikap ilmiah (Putra dkk., 2016).

Hasil belajar merupakan capaian yang diperoleh siswa dari pengalaman maupun proses pembelajaran dalam kegiatan belajar yang menyangkut sikap ilmiah, keterampilan proses dan pengetahuan (Widyarini dan Wilujeng, 2015). Hasil belajar terjadi akibat adanya evaluasi yang dilakukan oleh guru bukan hanya bergantung pada apa yang telah disampaikan oleh guru, tetapi dipengaruhi juga oleh hasil interaksi antara berbagai sumber informasi yang semestinya diberikan kepada siswa kemudian diolah oleh siswa berdasarkan pemahaman yang dimiliki sebelumnya.

Berdasarkan hasil observasi yang telah dilakukan sebelumnya kepada salah satu guru fisika di SMA Negeri 2 Jember bahwa pada saat proses pembelajaran siswa masih kurang aktif, siswa kurang tertarik terhadap metode pembelajaran yang diterapkan oleh gurunya dan siswa merasa jenuh terhadap pembelajaran fisika. Oleh karena itu, diperlukan adanya suatu model pembelajaran yang dapat melibatkan siswa pada saat kegiatan pembelajaran secara aktif dan menciptakan serta menerapkan ide-ide atau gagasan-gagasan baru yang dimilikinya.

Salah satu model pembelajaran yang dapat mendorong siswa agar aktif ialah suatu model yang dapat memberikan challenge (tantangan) untuk mengolah pikirannya ketika diberi suatu permasalahan. Margetson (1994) dalam Rusman (2014:230) megemukakan bahwa pembelajaran berbasis masalah dapat membantu dalam peningkatan keterampilan belajar seumur hidup dengan pola pikir yang terbuka, reflektif, kritis dan belajar aktif. Suatu pembelajaran yang dimulai dari suatu permasalahan, siswa dapat belajar tentang konsep sekaligus memecahkan masalah, meliputi jawaban dari masalah itu sendiri dan cara memecahkan msalah tersebut. Model pembelajaran yang sesuai untuk diterapkan ialah model Problem Based Learnig (PBL) dimana kegiatan pembelajaran lebih menekankan pada proses pemecahan masalah.

Pendekatan yang sesuai dengan model PBL ini salah satunya adalah STEM (Science, Technology, Engineering and Mathematics). Menurut Chesky dan Wolfmeyer (2015:4) STEM memiliki dua tujuan utama, yaitu (1) secara makro, berperan dalam kemajuan teknologi dan rekayasa yang diperlukan oleh suatu negara agar tetap bisa bersaing secara global dan (2) secara mikro, dapat membantu siswa memiliki pemahaman yang kuat mengenai tujuan, beberapa disiplin ilmu dan teknik yang ada di dalam pendekatan STEM, sehingga siswa dapat berpikir lebih mendalam dan kritis dalam menyelesaikan permasalahan yang dikaitkan dengan kehidupan nyata.

Berdasarkan latar belakang yang telah disampaikan sebelumnya, tujuan dari penelitian ini ialah untuk mengetahui peningkatan hasil belajar siswa sebelum dan sesudah menggunakan model PBL dengan pendekatan STEM.

\section{METODE}

Jenis penelitian ini adalah penelitian ekperimen dengan tempat penelitian telah ditentukan dengan menggunakan purposive sampling area yaitu di SMA Negeri 2 Jember. Penentuan sampel penelitian ditentukan menggunakan teknik purposive sampling dengan satu kelas dari beberapa kelas MIPA. Desain penelitian menggunakan pretest posttest control group design. Metode pengumpulan data yang digunakan dalam penelitian ini adalah tes. Teknik analisis data dalam mengolah hasil belajar siswa sebelum dan sesudah menggunakan model PBL dengan 
pendekatan STEM menggunakan persamaan $N$-gain sebagai berikut.

$$
N \text { gain }=\frac{s_{\text {Post }}-S_{\text {Pre }}}{100-S_{\text {Pre }}}
$$

Keterangan:

$N$ gain $=$ Normalized gain

$S_{\text {Pre }}=$ skor rata-rata seluruh siswa sebelum menggunakan model PBL dengan pendekatan

$S_{\text {Post }}=$ skor rata-rata sesluruh siswa sesudah menggunakan model PBL dengan pendekatan STEM

Tabel 1. Kriteria Peningkatan Hasil Belajar Siswa

\begin{tabular}{cc}
\hline Nilai $N$-gain & Kriteria \\
\hline$g \geq 0,70$ & High \\
\hline $0,30 \leq g<0,70$ & Medium \\
\hline$g<0,30$ & Low
\end{tabular}

(Hake dalam Wahyu dkk., 2010)

\section{HASIL DAN PEMBAHASAN}

Model PBL dengan pendekatan STEM merupakan kegiatan pembelajaran yang menekankan pada suatu masalah kehidupan sehari-hari yang berkaitan dengan science, technology, engineering and mathematics (Sari et al., 2018). Oleh karena itu, pembelajaran yang menggunakan model PBL dengan pendekatan STEM diharapkan dapat meningkatkan hasil belajar siswa SMA terhadap pembelajaran fisika.

Penelitian ini dilakukan selama tiga pertemuan dengan alokasi waktu 3 x 45 menit pada tiap pertemuan. Materi yang dibahas pada tiap pertemuan adalah tentang Vektor. Pada pertemuan 1 dan 2 guru memberikan materi tentang Vektor kemudian pada pertemuan 3, siswa melakukan tahapan sesuai dengan PBL dengan pendekatan STEM. Guru memberi LKS (Lember Kerja Siswa) mengenai Vektor dan sebelumnya guru sudah membagi siswa dalam beberapa kelompok.
Guru mendorong siswa untuk mencari informasi atau referensi mengenai masalah yang terdapat pada LKS dari berbagai sumber untuk menyelesaikan masalah pada LKS tersebut.

Siswa dibimbing untuk menyajikan solusi sementara terhadap permasalahan yang disajikan oleh guru, kemudian merancang atau mendesain sesuai dengan msolusi yang telah diajukan. Guru memberikan kesempatan kepada masingmasing kelompok untuk menyampaikan pendapatnya dalam menyelesaikan permasalahan, kemudian menganalisis kembali apa yang telah disampaikan. Setelah itu, siswa membuat rancangan yang sesungguhnya pada masing-masing LKS.

Berdasarkan penelitian yang sudah dilakukan, data hasil belajar fisika pada ranah kognitif yaitu diperoleh melalui tes yang dilakukan sebelum dan sesudah kegiatan pembelajaran menggunakan model PBL dengan pendekatan STEM. Data hasil belajar siswa dapat dilihat pada Tabel 2 .

Tabel 2. Ringkasan nilai pre-test dan post-

\begin{tabular}{lcc}
\multicolumn{2}{c}{ test } \\
& Sebelum & Sesudah \\
\hline Nilai rata-rata & 80,67 & 90,67 \\
\hline Nilai tertinggi & 96 & 100 \\
\hline Nilai terendah & 58 & 60 \\
\hline \multicolumn{2}{l}{ Pada Tabel 2 terlihat bahwa hasil belajar }
\end{tabular}
pada ranah kognitif sebelum dan sesudah diberi pembelajaran menggunakan model PBL dengan pendekatan STEM. Nilai ratarata pada sebelum dan sesudah diberi perlakuan masing-masing adalah 80,67 dan 90,67; sehingga diperoleh hasil analisis menggunakan $N$-gain diperoleh nilai $g$ adalah 0,517 yang berarti bahwa peningkatan hasil belajar siswa termasuk pada kategori medium (sedang). Hal tersebut sesusai dengan penelitian yang telah 
dilakukan oleh Lestari et al (2018) yang menyimpulkan bahwa LKS dengan pendekatan STEM dapat meningkatkan kemampuan berpikir kritis siswa yang dilihat dari perolehan nilai $N$-gain sebesar 0,5 . Dengan demikian, dapat dinyatakan bahwa rata-rata kemampuan kognitif siswa menjadi lebih baik dan mengalami suatu

\section{KESIMPULAN}

Berdasarkan hasil analisis data yang diperoleh dan pembahasan pada bab sebelumnya, dapat disimpulkan bahwa model PBL dengan pendekatan STEM dapat meningkatkan hasil belajar siswa pada ranah kognitif dalam pembelajaran fisika di kelas $X$ MIPA 6 SMA Negeri 2 Jember.

Saran yang dapat peneliti berikan kepada para pembaca ataupun peneliti selanjutnya, adalah kegiatan pembelajaran yang menggunakan model PBL dengan pendekatan STEM akan berjalan baik apabila saat pelaksanaannya peneliti dapat mengarahkan siswa dengan baik dan memberikan penguatan pada akhir pembelajaran, sehingga dapat dijadikan alternatif solusi apabila siswa menemukan masalah yang serupa pada pembelajaran fisika di kelas, serta dapat dijadikan dasar untuk mengembangkan model maupun metode yang sesuai untuk diterapkan dalam kegiatan pembelajaran pada penelitian selanjutnya.

\section{DAFTAR PUSTAKA}

Centaury, B. 2015. Pengembangan Perangkat Pembelajaran Fisika Berbasis Inkuiri Pada Materi Optik dan Indikator Dampak terhadap Kompetensi Siswa Kelas X SMA. Jurnal Riset dan Edukasi Sains. 1(2) : 80-91.

Chesky N.Z dan M.R. Wolfmeyer. 2015. Philosophy of STEM Education: A peningkatan. Hal tersebut membuktikan bahwa model PBL dengan pendekatan STEM dapat meningkatkan kemampuan kognitif siswa karena pada model PBL dengan pendekatan STEM lebih menekankan pada kebermaknaan suatu pembelajaran dan permasalahan yang disajikan berkaitan dengan kehidupan nyata. Critical Inveatigation. United States: Palgrave Macmillan.

Lestari, D.A.B., B. Astuti dan T. Darsono. 2018. Implementasi LKS dengan Pendekatan STEM (Science, Technology, Engineering and Mathematics) untuk Meningkatkan Kemampuan Berpikir Kritis Siswa. Jurnal Pendidikan Fisika dan Teknologi. 4(2): 202-207.

Putra, A. G. P., S. Bektiarso dan R.D. Handayani. 2016. Pengaruh Model Problem Based Learning (PBL) Terhadap Hasil Belajar dan Keterampilan Proses Sains dalam Pembelajaran Fisika di SMA (Kelas X Sma Negeri 3 Jember). Jurnal Pembelajaran Fisika. 5(2) : 129-134.

Rusman. 2014. Model-model Pembelajaran Mengembangkan Profesionalisme Guru (Edisi Kedua). Jakarta: Rajawali Press.

Sari, U., M. Alici dan O. F. Sen. 2018. The Effect of STEM Instruction on Attitude, Career Perception and Career Interest in a Problem-based Learning Environment and Student Opinions. Electronic Journal of Science Education. 22(1): 1-18.

Trianto. 2010. Design of Innovative Learning Model - Progressive. Jakarta: Kencana Predana Media Group. 
Wahyu, W., W. Sopandi dan E. Kusniat. 2019. Study of Project-based Learning (PjBL) on Self-Efficacy and Academic Achievement of $\mathrm{pH}$ Range Natural Indicator Learning in Chemistry Classroom. Dalam Empowering Science and Mathematics Competitiveness for Global
Rahmawati dan P.C. Taylor. London: CRC Press Taylor and Francis Group.

Widyarini, A., dan I. Wilujeng. 2015. Pengembangan LKS IPA Berbasis Scientific Approach untuk Mengoptimalkan Learning Outcome Siswa MTs Kelas VII. Jurnal Pendidikan Matematika dan Science. 3 (2): 169-181. 